\title{
Detecting Residual Fluorine 18 From a Medical PET-CT Procedure During Population Whole Body Counter Screening in Fukushima
}

\author{
Yoshitaka Nishikawa, MD; Masaharu Tsubokura, MD'; Shigeaki Kato, PhD; \\ Takeaki Ishii, MD; Yasutoshi Saito, MD, PhD
}

A fter the Fukushima Daiichi nuclear incident in 2011, radiation contamination of the affected area raised public health concerns about internal radiation exposure. ${ }^{1}$ Internal radiation exposure screening using a whole body counter (WBC) (Fastscan Model 2251, Canberra Inc, Meriden, CT) has been performed for the affected residents in Soma City, $40 \mathrm{~km}$ north of the Fukushima Daiichi nuclear power plant (Figure 1). Analysis was performed by use

\section{FIGURE 1}

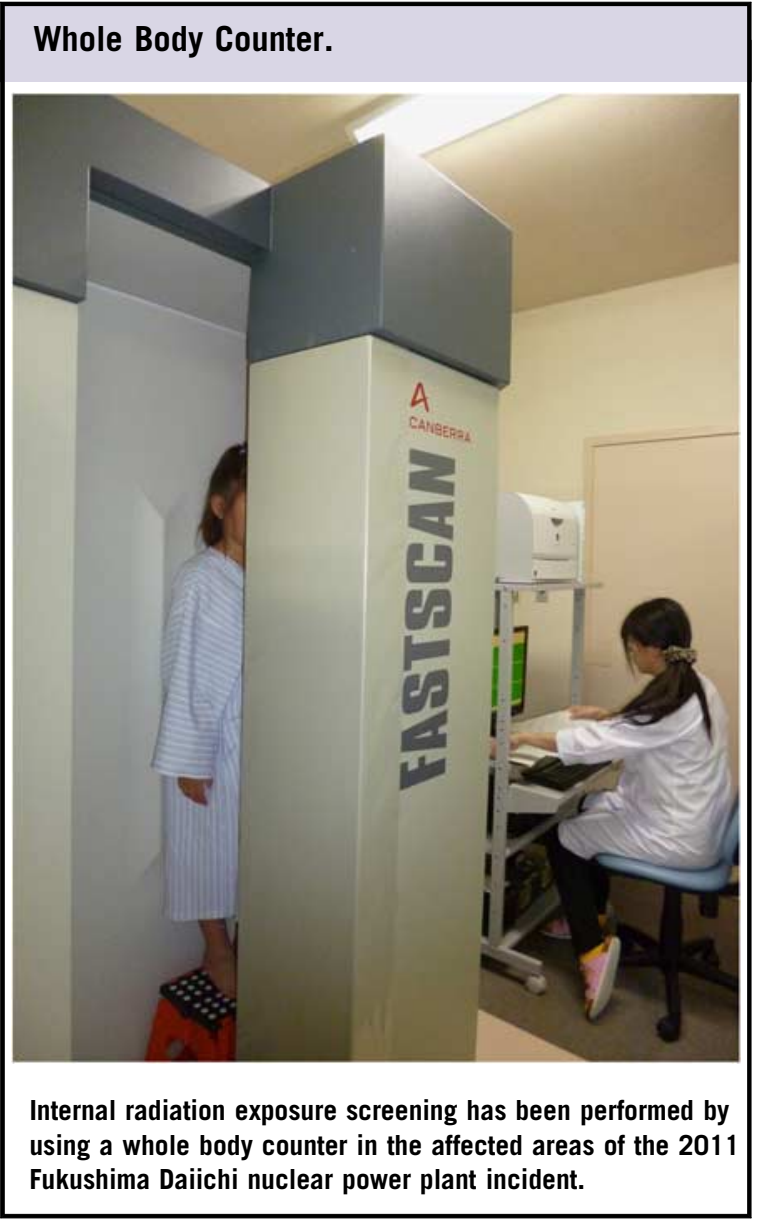

of the Apex-InVivo and Genie software (Canberra Inc). Detection limits were $220 \mathrm{~Bq}$ for cesium 134 and $250 \mathrm{~Bq}$ for cesium 137 with a 2-minute scan.

During a WBC screening of a 63-year-old examinee, a prominent peak at $511 \mathrm{keV}$ was unexpectedly seen (Figure 2). Detailed history taking revealed that radioactive fluorine $18\left({ }^{18} \mathrm{~F}\right)$ fluorodeoxyglucose (FDG) was given to the patient the day before the WBC scan for the purpose of cancer screening by positron emission tomography (PET)/computed tomography (CT) scanning.

FDG-PET/CT scanning is a diagnostic imaging technology that uses the two $511-\mathrm{keV}$ gamma rays emitted at the moment of positron annihilation, ${ }^{2}$ and the detected peak evidently reflects the remaining $\left[{ }^{18} \mathrm{~F}\right]$ FDG. To our knowledge, this is the first report of detection of an $\left.{ }^{18} \mathrm{~F}\right] \mathrm{FDG}$ peak by WBC scanning.

Although the possibility of the presence of medical imaging and therapeutic radioactive isotopes has previously been described as a potential concern in homeland security screening, ${ }^{3,4}$ this case uncovered the undesirable aspect that FDG administered for PET/CT scanning shows a peak adjacent to those of target radionuclides for Fukushima Daiichi incident

\section{FIGURE 2}

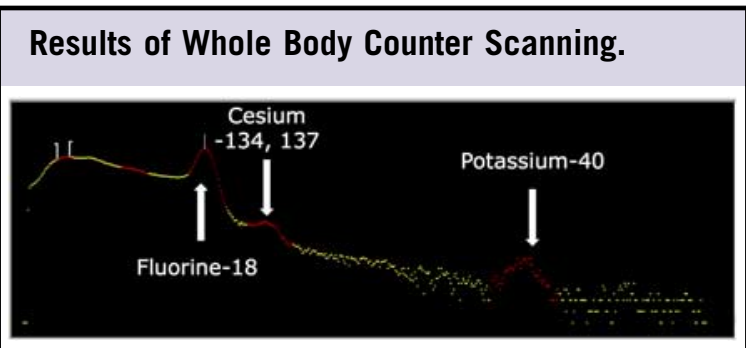

We unexpectedly detected a peak at $511 \mathrm{keV}$ (left arrow) that overlapped with the radioactive cesium peak (middle arrow). Potassium 40 was detected at an ordinary level of $1725 \mathrm{~Bq} /$ body (right arrow). 
response WBC screening, such as cesium 134 and cesium 137. Clinicians should be careful not to overestimate the peaks from these target nuclides.

Together with the previous findings about detection of iodine 131 administered for thyroid cancer treatment, ${ }^{5}$ the present results suggest that careful history taking is pivotal for accurate assessment of radiation contamination among residents living in the area affected by the nuclear disaster.

\section{About the Authors}

Department of Internal Medicine (Drs Nishikawa and Saito), Department of Radiation Protection (Drs Tsubokura and Kato), and Department of Orthopedic Surgery (Dr Ishii) Soma Central Hospital, Fukushima, Japan, and Division of Social Communication System for Advanced Clinical Research, Institute of Medical Science, The University of Tokyo, Tokyo, Japan (Dr Tsubokura).
Correspondence and reprint requests to Yoshitaka Nishikawa, Department of Internal Medicine, Soma Central Hospital, Fukushima, Japan 3-5-8, Okinouchi, Soma city, Fukushima, 976-0016, Japan (e-mail: ynishikawa-tky@umin.ac.jp).

\section{REFERENCES}

1. Tsubokura M, Gilmour S, Takahashi $\mathrm{K}$, et al. Internal radiation exposure after the Fukushima nuclear power plant disaster. JAMA. 2012;308:669-670.

2. Delbeke D, Coleman RE, Guiberteau MJ, et al. Procedure guideline for tumor imaging with 18F-FDG PET/CT 1.0. J Nucl Med. 2006;47: 885-895.

3. Dauer LT, Williamson MJ, St Germain J, et al. Tl-201 stress tests and homeland security. J Nucl Cardiol. 2007;14:582-588.

4. Gitler B. Re: Tl-201 stress tests and homeland security. J Nucl Cardiol. 2007;14:904.

5. Tsubokura M, Nomura S, Ishii T, et al. Detection of $131 \mathrm{I}$ in a patient with thyroid cancer by internal radiation exposure screening using a wholebody counter in Fukushima. Clin Nucl Med. 2014;39:281-282. 